\title{
Patterns and mechanisms of variable settlement and recruitment of a coral reef damselfish, Chromis cyanea
}

\author{
Todd W. Anderson ${ }^{1,2, * * *}$, Mark H. Carr ${ }^{1,3}$, Mark A. Hixon ${ }^{1}$ \\ ${ }^{1}$ Department of Zoology, Oregon State University, Corvallis, Oregon 97331-2914, USA
}

${ }^{2}$ Present address: Department of Biology, San Diego State University, San Diego, California 92182-4614, USA

${ }^{3}$ Present address: Department of Ecology and Evolutionary Biology, University of California, Santa Cruz, California 95064, USA

\begin{abstract}
Distinguishing the relative contributions of various processes to variation in recruitment success is central to our understanding of patterns and rates of population replenishment in marine organisms. We monitored settlement and recruitment of a common Caribbean damselfish, the blue chromis Chromis cyanea, to ascertain the extent to which variation in recruitment reflected settlement dynamics. Daily settlement and weekly recruitment were censused on coral heads for $1.5 \mathrm{mo}$ at each of 2 reefs separated by $7 \mathrm{~km}$. We also conducted manipulations of resident conspecifics to test for intraspecific effects on patterns of settlement and recruitment. Temporal variation in settlement between the 2 reefs coincided with the new moon, but peak settlement at one reef lagged the other by 7 to $10 \mathrm{~d}$ over 2 settlement periods. Such variation may have been caused by longshore current flow delivering patches of larvae to the reefs in sequence or by high current velocities at one reef coinciding with the new moon that may inhibit and delay settlement. Weekly recruitment was marginally higher than but unrelated to cumulative daily settlement, indicating possible recruitment facilition. In subsequent experimental manipulations settlement occurred only where conspecifics were present and was inversely density-dependent. Observed early post-settlement mortality of $C$. cyanea on continuous fore-reef was density-dependent, which is consistent with patterns of mortality for this species previously reported on patch reefs. Combining rates of input (resident-facilitated settlement) with rates of output (density-dependent mortality) of $C$. cyanea suggests that both resident conspecifics and predators play a role in the abundance and regulation of local populations.
\end{abstract}

KEY WORDS: Settlement · Recruitment facilitation · Reef fish · Chromis cyanea Resale or republication not permitted without written consent of the publisher

\section{INTRODUCTION}

Identifying the processes responsible for variation in the demographic rates of populations and how such processes vary through time and space is crucial to our understanding of population dynamics (Cappuccino \& Price 1995). For many marine organisms that exhibit a complex life history, reproduction may be largely decoupled from the input of new individuals in local populations despite evidence of some degree of selfrecruitment (e.g. Jones et al. 1999, Almany et al. 2007). Thus, 'settlement' as the immediate transition of pe- lagic stage larvae to benthic habitats is analogous to births in these relatively open populations and, coupled with the effects of post-settlement processes after some period of time, yields 'recruitment' to a local population.

For marine fishes the early life history leading up to recruitment is considered a critical stage in their population structure and dynamics (e.g. Sissenwine 1984, Myers \& Cadigan 1993). Reef fishes in particular have been a major focus in studies of processes affecting recruitment (for reviews see Doherty 2002, Hixon \& Webster 2002). The magnitude and variation in the delivery of larvae to a location as a result of pre-settle- 
ment processes may be reinforced through densityindependent mortality (Doherty 2002), or modified by post-settlement density-dependent mortality (Hixon \& Webster 2002).

Patterns of settlement of reef fishes are a result of oceanographic processes and larval behaviors that influence larval dispersal and mortality and deliver larvae differentially to benthic habitats (e.g. Caselle \& Warner 1996). At smaller spatial scales, settlement may be a result of several processes, including topographically modified current flow (Wolanski \& Hamner 1988), current velocity (Schmitt \& Holbrook 2002), encounter rates with available habitat (Jones 1997), larval behavior (Leis \& McCormick 2002) and habitat selection (Holbrook \& Schmitt 1997). Moreover, settlement to habitats may be influenced by the presence and density of resident conspecifics, resulting in recruitment facilitation or inhibition (reviewed by Hixon \& Webster 2002).

We examined variation in recent settlement and recruitment of a coral reef damselfish, the blue chromis Chromis cyanea, within and between reefs in the central Bahamas. Chromis cyanea generally settles to fore-reefs, forming site-attached aggregations of individuals above coral heads. We asked 3 questions: (1) What are the temporal and spatial patterns of recent settlement of C. cyanea within and between continuous coral reefs? (2) Does recruitment over 1 wk periods reflect recent settlement? (3) Does the presence and number of resident conspecifics influence recent settlement to coral heads (i.e. is there evidence for recruitment facilitation) and, if so, is such an effect related to the density of conspecifics? We used C. cyanea as a model to explore these questions because it is one of the most abundant reef fishes in the central Bahamas, recruits are fairly sedentary and remain near coral heads to which they first settle, young fish are conspicuous and, thus, easy to count and recent settlers can be distinguished from older recruits by both color and size.

\section{METHODS}

Study system. We conducted studies from 1 July through 16 August 1997 and from 29 May to 14 June 1999 at Lee Stocking Island (LSI), the Bahamas (for a general description of the study area, see Carr \& Hixon 1995). Two reefs, 'South Bock' and 'SE LSI', were selected for monitoring settlement and recruitment of Chromis cyanea (see Anderson et al. 2002 for map of locations). South Bock was located near a cay northwest of LSI, where Agaricia tenuifolia was the predominant coral and tidal currents were moderate to strong. By contrast, SE LSI was located along the southeast edge of LSI, where Montastrea spp. and Pocillopora spp. were the most common corals and current velocity was low. The areas of reef studied were at depths of 10 to $12 \mathrm{~m}$. Longshore currents flowed from SE LSI toward South Bock, $7 \mathrm{~km}$ to the northwest.

Settlement and recruitment. Because we could not observe settlement directly, we define 'recent settlement' operationally as the first appearance of settlers on a coral head within $24 \mathrm{~h}$ of a previous census of that coral head. Therefore, we cannot account for any changes in mortality of settlers between biological settlement and our first observations of settlers. This interval may have been only a few hours because most coral reef fishes are thought to settle during the night. Newly settled recruits may move among adjacent coral heads but do not appear to move substantially after settlement and we attributed the decline of recruits observed over short periods of time to mortality and not emigration. We define 'recruitment' in this study as the number of settlers that remain on coral heads after $7 \mathrm{~d}$, a period during which Chromis cyanea experiences very high post-settlement mortality (Carr \& Hixon 1995, Hixon \& Carr 1997).

By 30 June 1997, all existing recruits of Chromis cyanea were cleared from each of 30 coral heads at both reefs using a BINCKE net (Anderson \& Carr 1998), with the exception of 1 or 2 recruits used as 'seeds' to potentially encourage settlement (Carr \& Hixon 1995). Observers monitored recent settlement of C. cyanea to coral heads daily from 1 July to 16 August 1997 at South Bock and at SE LSI. Coral heads to which no settlement was observed over the study period were excluded from estimations of the density of settlers (number per coral head) because such heads may have represented unsuitable habitat and their inclusion would have underestimated the magnitude of recent settlement. Finally, we documented mortality by observing daily losses of recruits at these same coral heads at SE LSI over $10 \mathrm{~d}$ (16 to 26 August at SE LSI) when settlement did not occur, using only coral heads at which at least 6 C. cyanea were present on 16 August ( $\mathrm{n}=8$ coral heads) for a reasonable estimate of proportional mortality.

To determine whether weekly periods of recruitment (accumulation of settlers over $7 \mathrm{~d}$ ) corresponded to daily cumulative recent settlement (the weekly sum of the number of settlers counted daily but removed each day), we conducted a removal experiment. Our goal for this experiment was both logistical and biological in nature; if recruitment over $1 \mathrm{wk}$ reflected daily cumulative recent settlement for that period, less effort would be required to study patterns of settlement and recruitment among reefs at larger spatial scales. Furthermore, this experiment allowed us to examine the potential for recruitment facilitation or inhibition as interactions among conspecifics that might influence the magnitude of recent settlement. 
We conducted four $1 \mathrm{wk}$ trials in July and August that bracketed peak settlement at each reef (SE LSI: 1 to 7 July and 29 July to 4 August; South Bock: 8 to 14 July and 5 to 11 August). Coral heads at each reef were assigned randomly to 1 of 2 treatments: cumulative daily settlement ( $\mathrm{n}=20$ coral heads) or weekly recruitment ( $\mathrm{n}=10$ coral heads). More coral heads were employed for daily settlement than for weekly recruitment because we expected greater spatial variation in daily settlement. For a given week, new settlers were removed immediately after being recorded on each of the 20 coral heads, censused daily. For the remaining 10 coral heads, settlers were also recorded daily, but removed only at the end of the 1 wk period.

Recruitment facilitation. Based on observations of recent settlement and recruitment, we conducted an experiment to determine whether patterns of recent settlement were positively related to the presence and local density of conspecifics. We selected 20 coral heads at SE LSI and removed all Chromis cyanea from 10 randomly selected coral heads on 29 to 31 May and on 4 to 5 June 1999. For another 5 randomly selected coral heads, we removed two-thirds of resident $C$. cyanea if the number of fish was greater than 5, but removed only one-half of the residents if they numbered less than 5 . For the remaining 5 coral heads we did not remove any resident C. cyanea. These manipulations resulted in 10 coral heads with zero residents and 10 other coral heads with $3,4,5,6,11,12,17,20$, 30 and 40 residents at the initiation of the experiment. Importantly, we employed partial removals of $C$. cyanea to alter the existing rank order in the number of residents among coral heads so that a positive relationship between numbers of resident $C$. cyanea and new settlers indicating recruitment facilitation would not be potentially confounded by habitat quality or local environmental processes that might simply deliver more or less settlement-stage larvae to particular coral heads. A preliminary survey of coral heads was done on 7 June 1999 to ensure the integrity of treatments and to record that no individuals had settled to coral heads for which there was complete removal of $C$. cyanea. Observers counted the number of new settlers found on coral heads daily for a $1 \mathrm{wk}$ period from 8 to 14 June 1999. On each daily census, new settlers were removed from all coral heads.

Analyses. Settlement and recruitment: We first inspected temporal patterns of settlement between reefs relative to the lunar cycle and used correlation analysis to determine if there was temporal concordance in recent settlement between reefs. A 2-way analysis of variance (ANOVA) was used to determine whether there were differences in settlement between reefs and between treatment of coral heads (weekly recruitment vs. cumulative daily settlement). To determine whether mortality rates of Chromis cyanea over the $10 \mathrm{~d}$ period from 16 to 26 August at SE LSI were density-dependent, we regressed proportional mortality on recruit density.

Recruitment facilitation: Because of severe heteroscedasticity, we could not employ a $t$-test to first examine whether the number of settlers on coral heads with resident conspecifics differed from those on unoccupied coral heads. Instead, we determined whether the zero value for coral heads without residents (i.e. no settlement occurred) was within the 95\% confidence intervals of the mean number of settlers to coral heads with resident conspecifics. If not, settlement was interpreted to be significantly different between coral heads with and without residents. For the 10 coral heads at which resident Chromis cyanea were present, we used linear regression to further examine the relationship between the number of resident conspecifics on coral heads and the total number of settlers observed during the experiment.

Finally, we compared the total rates of settlement (number of settlers per coral head) during this experiment with total rates of mortality (number of individuals that disappeared per coral head) documented from 16 to 26 August across similar densities. An intersection of these 2 curves as inputs and outputs (see Hixon \& Webster 2002) in this species would suggest that both settlement and mortality rates may regulate local populations of Chromis cyanea.

\section{RESULTS}

During the 6 wk of observed settlement, recent settlement of Chromis cyanea to SE LSI and South Bock showed strong lunar periodicity, with relatively high settlement near the 2 new moon phases and virtually no settlement during the full moon (Fig. 1). Using dates on

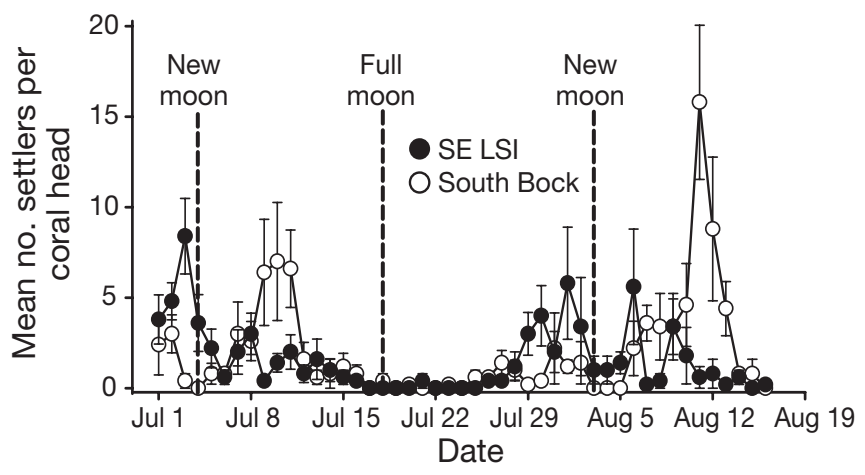

Fig. 1. Chromis cyanea. Mean recent settlement $( \pm \mathrm{SE})$ to coral heads at southeast edge of Lee Stocking Island (SE LSI) and South Bock over 1.5 mo in 1997. Vertical dashed lines denote moon phase of the lunar cycle 
which settlement occurred at one or both reefs, however, there was no temporal concordance in settlement between SE LSI and South Bock $(\mathrm{r}=-0.08, \mathrm{p}=0.58, \mathrm{n}=$ 43). Peak settlement at South Bock occurred 7 and $10 \mathrm{~d}$ after peak settlement at SE LSI for each of the 2 new moon lunar phases, respectively, revealing a consistent pattern of temporal variation in settlement between these 2 reefs. When settlement on each date at South Bock was shifted forward in time by $7 \mathrm{~d}$ and compared with the actual census date at SE LSI, settlement at South Bock was significantly correlated with settlement at SE LSI $(r=0.36, p=0.02, n=39)$.

There was no difference in the magnitude of settlement of Chromis cyanea between SE LSI and South Bock reefs, whereas a strong trend was apparent between coral heads in which settlers were removed daily and those that were allowed to accumulate settlers for $1 \mathrm{wk}$ to estimate recruitment (2-way ANOVA for reef: $F_{1,32}=1.50, \mathrm{p}=0.23$; for coral head treatment: $F_{1,32}=3.36, \mathrm{p}=0.08$; for reef $\times$ treatment interaction: $F_{1,32}=2.40, \mathrm{p}=0.13$ ). For four 1 wk periods in July and August that bracketed peak settlement at each reef (SE LSI: 1 to 7 July and 29 July to 4 August; South Bock: 8 to 14 July and 5 to 11 August), there were nominally higher numbers of $C$. cyanea that accumulated on coral heads for $1 \mathrm{wk}$ than for the cumulative number of settlers for that same period but removed daily for 3 of these 4 periods (Fig. 2).

Monitoring of recruits over a $10 \mathrm{~d}$ period near the end of the study when settlement did not occur showed

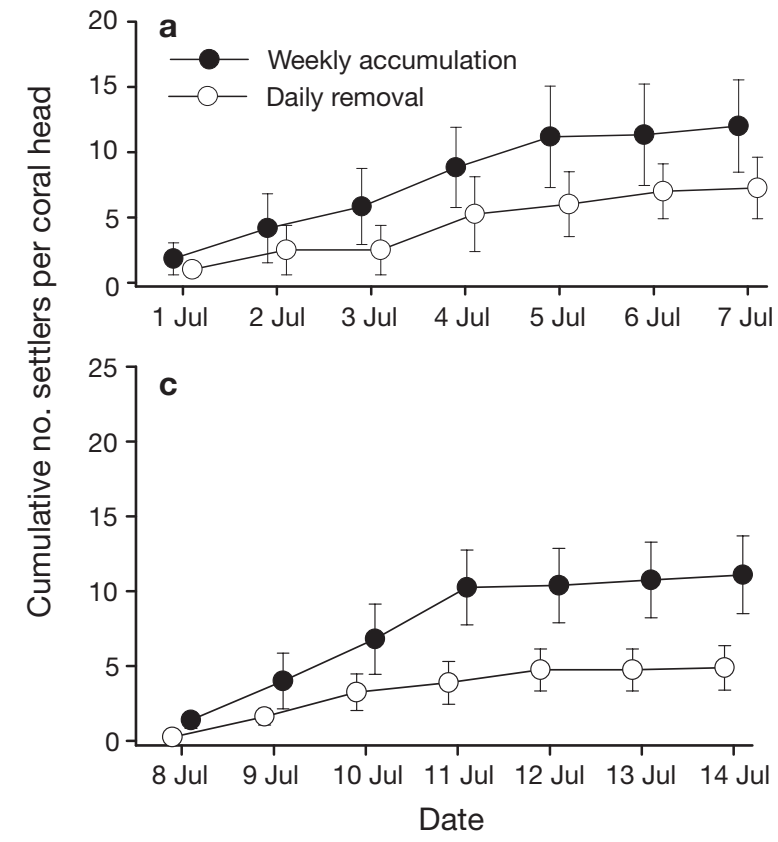

appreciable losses of recruits. Because recruits of Chromis cyanea did not appear to move more than a few meters at most from the coral heads on which they settled (T. W. Anderson pers. obs., also see Sandin \& Pacala 2005), we attributed these disappearances to mortality. Based on our observations, loss of recruits during this period was density-dependent $\left(\mathrm{r}^{2}=0.64, \mathrm{p}=0.01, \mathrm{n}=8\right.$; Fig. 3).

Our experiment testing for recruitment facilitation produced definitive results. Recent settlement occurred only on coral heads with resident conspecifics and not on unoccupied coral heads (mean settlement to coral heads with residents $=5.5,95 \%$ confidence inter$\mathrm{val}=1.74-9.23$; Fig. 4a), revealing a significant difference in settlement. In addition, recent settlement (number of settlers) was strongly density-dependent (Fig. 4b), with $96 \%$ of the variation in settlement explained by the mean number of resident conspecifics $\left(\mathrm{r}^{2}=0.96, \mathrm{p}=0.0001, \mathrm{n}=10\right)$. When combining rates of resident-facilitated settlement with observed rates of density-dependent mortality across similar densities of resident recruits (Fig. 5), the 2 curves intersected, indicating population regulation.

\section{DISCUSSION}

Considerable variability in settlement and recruitment is commonly observed in marine organisms that exhibit a complex life history in which early life stages
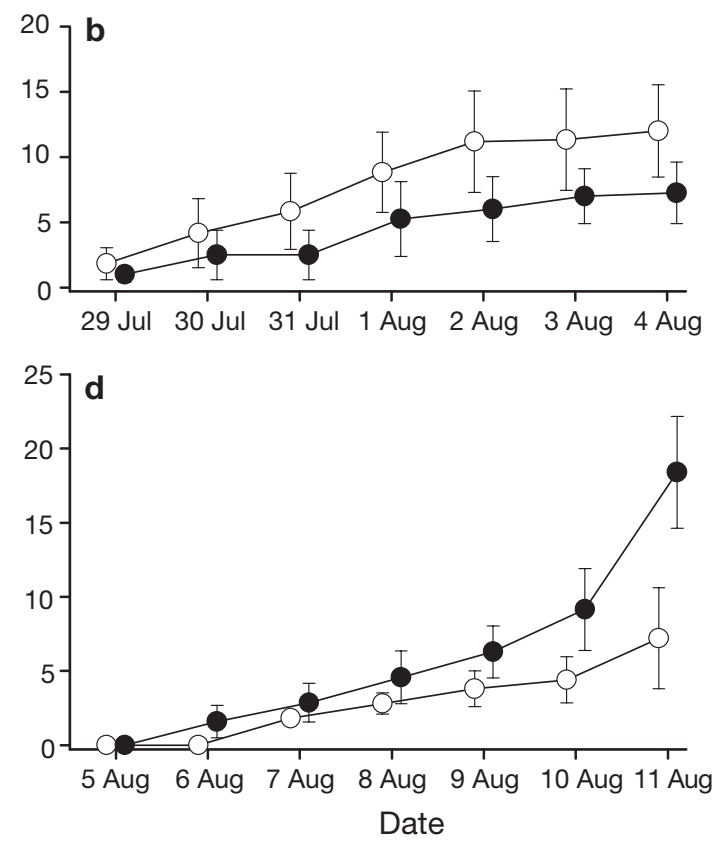

Fig. 2. Chromis cyanea. Mean $( \pm \mathrm{SE})$ cumulative daily settlement (daily removal of settlers) and weekly recruitment (weekly accumulation of settlers) to coral heads over two 1 wk periods of peak settlement at (a,b) SE LSI and (c,d) South Bock. Mean values for daily settlement and weekly recruitment are offset for each date to clearly show bars representing SE 


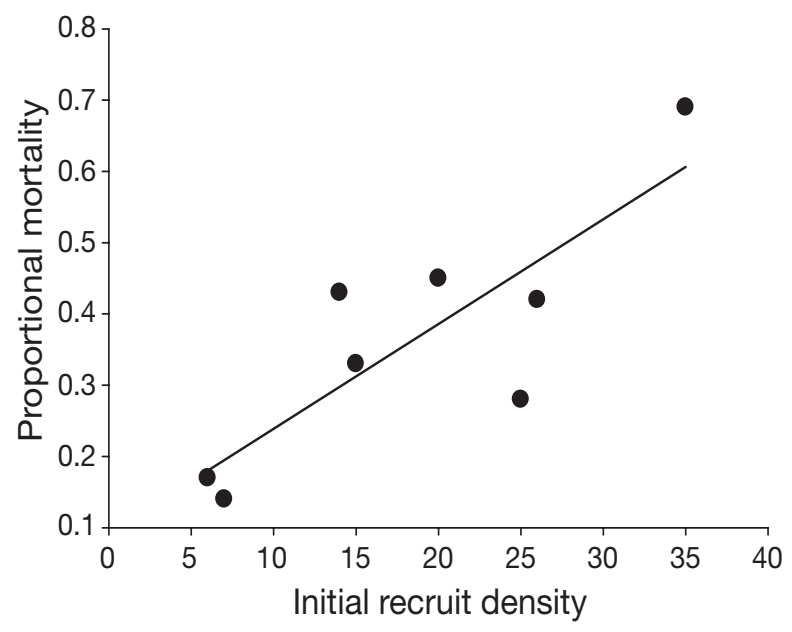

Fig. 3. Chromis cyanea. Relationship between proportional mortality and initial densities of recruits over a $10 \mathrm{~d}$ period (16 to 26 August 1997) when settlement did not occur
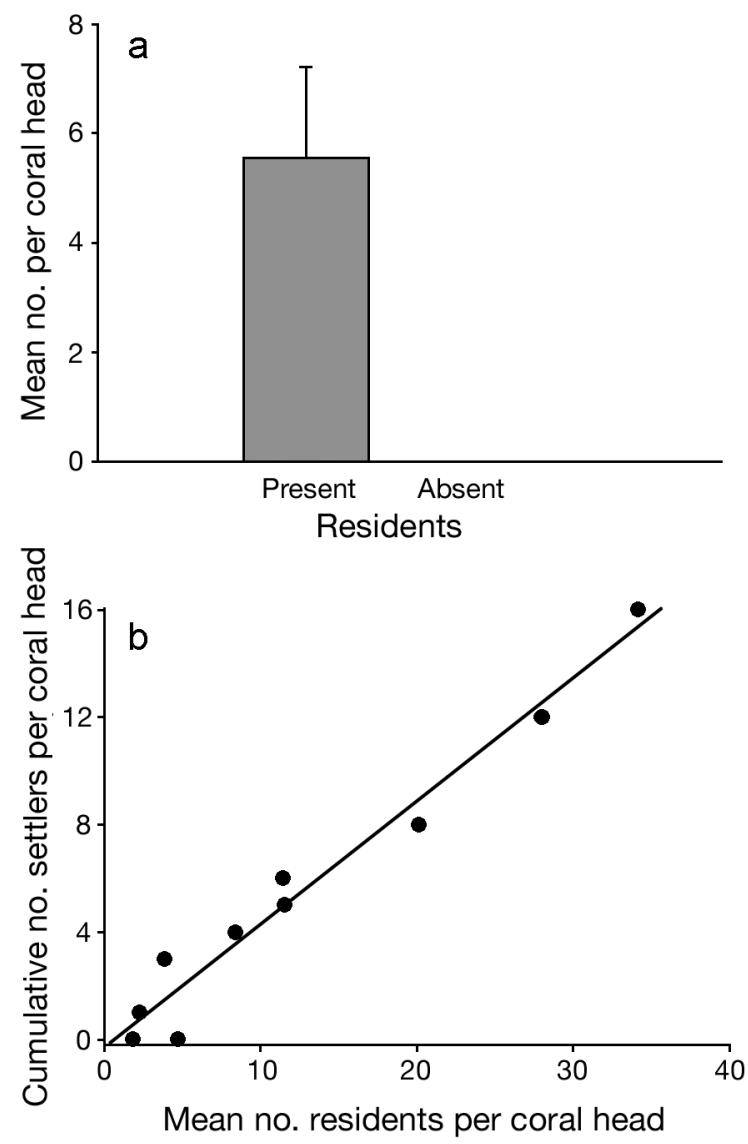

Fig. 4. Chromis cyanea. (a) Mean $( \pm \mathrm{SE})$ number of settlers on coral heads in the presence and absence of resident conspecifics, and (b) the relationship between the cumulative number of settlers and the mean number of resident conspecifics on coral heads over a $1 \mathrm{wk}$ period of settlement at SE LSI

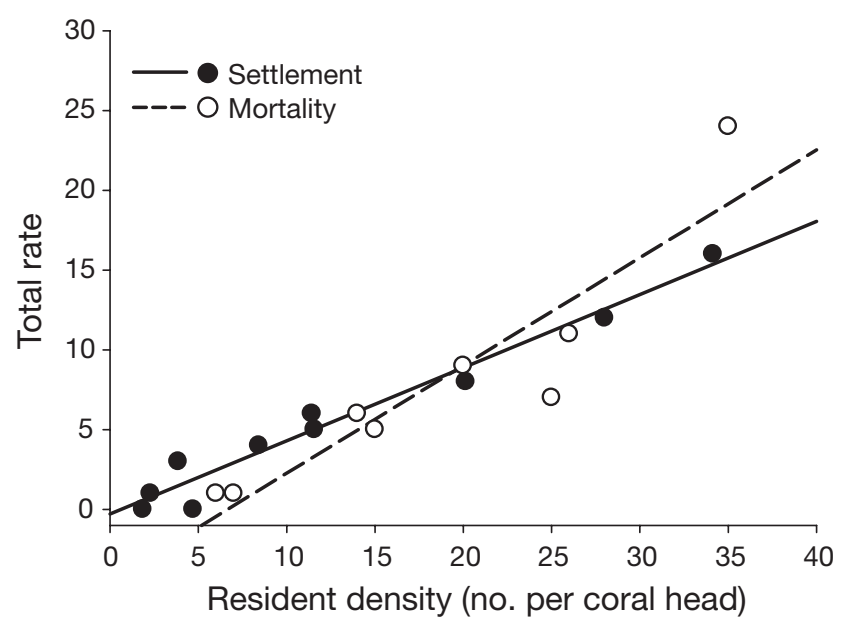

Fig. 5. Chromis cyanea. Relationships between the total rates of recent settlement (no. settlers per coral head) and mortality (no. disappeared per coral head) versus the density of resident conspecifics. Note that the curves for resident-facilitated settlement and density-dependent mortality intersect, suggesting local population regulation

are separated spatially from resident local populations of older individuals. Sources of variation in settlement and recruitment include large-scale oceanographic features that affect the delivery of larvae (e.g. Cowen 2002), smaller-scale patterns of current flow and velocity as larvae approach benthic habitats (Schmitt \& Holbrook 2002), settlement cues and habitat selection (Leis \& McCormick 2002), and a variety of postsettlement processes (Hixon \& Webster 2002).

Although spatial variation in settlement of reef fishes is expected, there is evidence for greater consistency in temporal variation. Concordance in settlement with the lunar cycle is a common phenomenon in many reef fishes (Robertson et al. 1992), and lunar periodicity may have an overriding effect on settlement even though oceanographic conditions can contribute to or modify its influence (Sponaugle \& Pinkard 2004). In the present study, lunar periodicity in Chromis cyanea was evident from peaks in settlement near the new moon. More interestingly, South Bock lagged SE LSI in peak settlement consistently by 7 to $10 \mathrm{~d}$ over 2 lunar cycles. The mechanism for this temporal lag in settlement at South Bock is unknown, but we present 2 possibilities: (1) longshore current flow from the southeast may deliver larval fish to South Bock about 1 wk later than to SE LSI, and (2) tidally driven current velocities at South Bock, which are 3 times higher than at SE LSI (Anderson et al. 2002), may inhibit settlement of fish near the new moon when current velocities should be highest.

Oceanographic conditions are a source of differential patterns of settlement or recruitment, including current flow and wind stress (Sponaugle \& Pinkard 
2004). Moreover, Caselle \& Warner (1996) have shown that gradients in recruitment of the bluehead wrasse Thalassoma bifasciatum coincide with opposite directional current flow between the windward and leeward sides of St. Croix, US Virgin Islands, suggesting that physical oceanographic processes are responsible for this pattern. At our SE LSI site, currents flow northward at a net mean velocity of $7 \mathrm{~cm} \mathrm{~s}^{-1}$ (N. Smith, Harbor Branch Oceanographic Institution, pers. comm.), a rate that would reach South Bock in less than $2 \mathrm{~d}$. These data do not support the hypothesis that larval delivery from the south is lagged by 7 to $10 \mathrm{~d}$, although it is possible that during our study currents flowed northward at a much slower speed. Currents flowing northward also flow westward and eastward with tidal flux between cays, and it is possible that the net northward movement of larvae is slowed in this manner. For current flow to be the mechanism of delayed settlement at South Bock, however, settlers delivered to both of our reefs must come from the same patch of larvae. One test of this hypothesis would be to determine whether settlers at South Bock are generally 7 to $10 \mathrm{~d}$ older than their counterparts at SE LSI, coinciding with the temporal lag in settlement between reefs.

The other scenario, that much higher current velocities inhibit settlement of Chromis cyanea at South Bock, may also be important. Even so, the relationship between settlement and current velocity may be complex. Three damselfishes (genus Dascyllus) exhibited differential responses in settlement with current speed across a series of lagoons that result in higher or lower settlement (Schmitt \& Holbrook 2002). Obviously, knowledge of the sources of settlement-stage larvae coupled with how oceanographic features distribute them and larval behavior will help to resolve the relative importance of these factors in both temporal and spatial patterns of settlement.

As expected, recent settlement of Chromis cyanea was variable among coral heads. Our results show, however, that the presence and number of resident conspecifics is a major source of spatial variation in settlement of $C$. cyanea. In this case, strong inversely density-dependent recruitment facilitation explained $96 \%$ of the variation in the number of settlers among coral heads. The lack of a clear relationship between cumulative daily settlement and weekly recruitment of $C$. cyanea within reefs, however, suggests that the weekly accumulation of settlers is not a good proxy for relative differences in recent settlement among reefs, at least for this species. We may have detected a stronger relationship had we been able to prevent access to coral heads by predators, but preliminary studies showed that $C$. cyanea avoid settlement within predator exclosures. Thus, recruitment facilitation that would increase the input of settlers and predator- induced mortality (Hixon \& Carr 1997) resulting in density-dependent losses of settlers may sufficiently alter an otherwise positive relationship between cumulative daily settlement and weekly recruitment.

Predation is now considered a major source of density dependence in reef fishes (Hixon \& Webster 2002). Chromis cyanea is subject to strong densitydependent mortality caused by predators on patch reefs (Hixon \& Carr 1997) in the Bahamas. In the present study, we also found evidence for densitydependent mortality in C. cyanea on continuous forereef. Recently, however, Sandin \& Pacala (2005) reported that predator-induced mortality of $C$. cyanea in the Netherlands Antilles at Curaçao and Bonaire is inversely density-dependent on continuous reefs, with per capita loss rates increasing in smaller aggregations of individuals. Using remote videography, they quantified predator visitation and strike rates that were also inversely density-dependent, consistent with patterns of mortality. In light of their results, Sandin \& Pacala (2005) suggested that 'smallscale spatial patterns of mortality are almost certainly not regulating $C$. cyanea populations on continuous coral reefs.'

Sandin \& Pacala's (2005) results and suggestions are in conflict with our findings on Chromis cyanea and in contrast to several studies, mostly on patch reefs, that have shown predator-induced density-dependent mortality (reviewed by Hixon \& Webster 2002). Multiple observational studies have been conducted on continuous reefs that did detect density-dependent mortality: the honeycomb grouper Epinephelus merra at Réunion Island (Letourneur et al. 1998) and both the bicolor damselfish Stegastes partitus and the bluehead wrasse at Barbados (Hunte von Herbing \& Hunte 1991, Tupper \& Hunte 1994). Considering experimental approaches, Carr et al. (2002) demonstrated that mortality of the bicolor damselfish was density-dependent on both patch reefs and continuous reefs in the Bahamas. Also, on continuous reefs in the Bahamas, Webster (2003) demonstrated density dependence in the fairy basslet Gramma loreto. As with blue chromis, both the bicolor damselfish and the fairy basslet occur in aggregations on continuous reefs and are largely planktivorous, and predation was responsible for this density dependence. In addition, small-scale experimental demonstrations of density-dependent mortality caused by predation were corroborated by recent observational studies at much larger whole-reef scales for 2 other species in the Bahamas: the bridled goby Coryphopterus glaucofraenum (Steele \& Forrester 2005) and bicolor damselfish (M. A. Hixon pers. obs.). Finally, a variety of previously published studies have amply demonstrated little relationship between reef continuity per se and density dependence (Hixon \& 
Webster 2002). Taken together, there is little evidence that such patterns are necessarily habitat-dependent at the scale of patch reefs versus continuous reef, although there may be differential patterns of mortality for the same or different species at various locations.

The relative importance of multiple processes that drive the local abundances of marine species with complex life histories is difficult to assess. Gregarious settlement is a common phenomenon in marine invertebrates (e.g. Burke 1986) and reef fishes (see Hixon \& Webster 2002), and 2 of the benefits for such settlement are that resident conspecifics may serve as a cue for suitable habitat and aggregation may reduce the risk of predation. Chromis cyanea exhibits a clear pattern of inverse density-dependent (resident-facilitated) settlement, but it also is subject to strong densitydependent mortality (Hixon \& Carr 1997, present study). Observed higher settlement of C. cyanea to coral heads with increasing numbers of resident conspecifics could represent higher site quality that may disguise underlying density-dependent mortality (Shima \& Osenberg 2003). Although patterns of inverse density-dependent settlement and subsequent density-dependent mortality would seem to be in conflict, the processes that determine patterns of settlement may be unrelated to predation risk (Holbrook \& Schmitt 2003), and it is the relative strengths of the 2 demographic rates that determine net population dynamics. In this case, total rates of recent settlement and density-dependent mortality of C. cyanea intersect across similar densities of resident conspecifics, suggesting local population regulation in this damselfish (Hixon \& Webster 2002).

Acknowledgements. We thank G. Almany, C. Bartels, E. Bartels, C. McKinney-Richards, K. Overholtzer-McLeod, and $\mathrm{S}$. Whitcraft for field assistance and the staff of the Caribbean Marine Research Center (CMRC), especially B. Kakuk, for logistical support. This research and manuscript preparation was supported by grants from the National Science Foundation (OCE-96-17483 and OCE-00-93976 to M.A.H. and OCE99-96053 to M.H.C.) and NOAA's National Undersea Research Program through CMRC (97-3109 to M.A.H.) and through the West Coast and Polar Regions Center (UAF(CA)03-02 to T.W.A.).

\section{LITERATURE CITED}

Almany GR, Berumen ML, Thorrold SR, Planes S, Jones GP (2007) Local replenishment of coral reef populations in a marine reserve. Science 316:742-744

Anderson TW, Carr MH (1998) BINCKE: a highly efficient net for collecting reef fishes. Environ Biol Fishes 51:111-115

Anderson TW, Bartels C, Hixon MA, Bartels E, Carr MH, Shenker (2002) Current velocity and catch efficiency in sampling settlement-stage larvae of coral-reef fishes. Fish Bull 100:404-413
Burke RD (1986) Phermones and the gregarious settlement of marine invertebrate larvae. Bull Mar Sci 39:323-331

Cappuccino N, Price PW (1995) Populaton dynamics: new approaches and synthesis. Academic Press, San Diego, CA

Carr MH, Hixon MA (1995) Predation effects on early postsettlement survivorship of coral-reef fishes. Mar Ecol Prog Ser 124:31-42

Carr MH, Anderson TW, Hixon MA (2002) Biodiversity, population regulation, and the stability of coral-reef fish communities. Proc Natl Acad Sci 99:11241-11245

Caselle JE, Warner RR (1996) Variability in recruitment of coral reef fishes: the importance of habitat at two spatial scales. Ecology 77:2488-2504

Cowen RK (2002) Larval dispersal and retention and consequences for population connectivity. In: Sale PF (ed) Coral reef fishes: dynamics and diversity in a complex ecosystem. Academic Press, San Diego, CA, p 149-170

Doherty PJ (2002) Variable replenishment and the dynamics of reef fish populations. In: Sale PF (ed) Coral reef fishes: dynamics and diversity in a complex ecosystem. Academic Press, San Diego, CA, p 261-293

Hixon MA, Carr MH (1997) Synergistic predation, density dependence, and population regulation in marine fish. Science 77:946-949

Hixon MA, Webster MS (2002) Density dependence in reef fish populations. In: Sale PF (ed) Coral reef fishes: dynamics and diversity in a complex ecosystem. Academic Press, San Diego, CA, p 303-325

Holbrook SJ, Schmitt RJ (1997) Settlement patterns and process in a coral reef damselfish: in situ nocturnal observations using infrared video. Proc 8th Coral Reef Symp 2: $1143-1148$

Holbrook SJ, Schmitt RJ (2003) Spatial and temporal variation in mortality of newly settled damselfish: patterns, causes and co-variation with settlement. Oecologia 135: 532-541

Hunt von Herbing I, Hunte W (1991) Spawning and recruitment of the bluehead wrasse Thalassoma bifasciatum in Barbados, West Indies. Mar Ecol Prog Ser 72:49-58

Jones GP (1997) Relationships between recruitment and postrecruitment processes in lagoonal populations of two coral reef fishes. J Exp Mar Biol Ecol 213:231-246

Jones GP, Milicich MJ, Emslie MJ, Lunow C (1999) Selfrecruitment in a coral reef fish population. Nature 402: 802-804

Leis JM, McCormick MI (2002) The biology, behavior, and ecology of the pelagic, larval stage of coral reef fishes. In: Sale PF (ed) Coral reef fishes: dynamics and diversity in a complex ecosystem. Academic Press, San Diego, CA, p 171-199

Letourneur YP, Chabanet P, Vigliola L, Harmelin-Vivien M (1998) Mass settlement and post-settlement mortality of Epinephelus merra (Pisces: Serranidae) on Réunion coral reefs. J Mar Biol Assoc UK 78:307-319

Myers RA, Cadigan NG (1993) Density-dependent juvenile mortality in marine demersal fish. Can J Fish Aquat Sci 50: 1576-1590

Robertson DR (1992) Patterns of lunar settlement and recruitment in Caribbean reef fishes at Panama. Mar Biol 114: 527-537

Sandin SA, Pacala SW (2005) Fish aggregation results in inversely density-dependent predation on continuous coral reefs. Ecology 86:1520-1530

Schmitt RJ, Holbrook SJ (2002) Spatial variation in concurrent settlement of three damselfishes: relationships with nearfield current flow. Oecologia 131:391-401 
Shima JS, Osenberg CW (2003) Cryptic density dependence: effects of covariation between density and site quality in reef fish. Ecology 84:46-52

Sissenwine MP (1984) Why do fish populations vary? In: May RM (ed) Exploitation of marine communities. SpringerVerlag, New York, p 59-94

Sponaugle S, Pinkard D (2004) Lunar cyclic population replenishment of a coral reef fish: shifting patterns following oceanic events. Mar Ecol Prog Ser 267:267-280

Steele MA, Forrester GE (2005) Small-scale field experiments

Editorial responsibility: Otto Kinne (Editor-in-Chief), Oldendorf/Luhe, Germany accurately scale up to predict density dependence in reef fish populations at large scales. Proc Natl Acad Sci 102: 13513-13516

Tupper M, Hunte W (1994) Recruitment dynamics of coral reef fishes in Barbados. Mar Ecol Prog Ser 108:225-235

Webster MS (2003) Temporal density dependence and population regulation in a marine fish. Ecology 84:623-628

Wolanski E, Hamner WM (1988) Topographically controlled fronts in the ocean and their biological influence. Science 241:177-181

Submitted: September 6, 2004; Accepted: June 29, 2007 Proofs received from author(s): October 31, 2007 